Jurnal Penelitian Hutan Tanaman Vol 18 No. 1, Juni 2021, 1-12

ISSN: 1829-6327, E-ISSN: 2442

Terakreditasi No: 21/E/KPT/2018

\title{
PERTUMBUHAN DUA KLON KARET ASAL BIBIT OKULASI DI KABUPATEN BANYUASIN, PROVINSI SUMATERA SELATAN \\ (Growth Performance of Two Rubber Budding Clones in Banyuasin District, South Sumatera Province)
}

\author{
Jamin Saputra \\ Pusat Penelitian Karet Sembawa \\ Jl. Raya Palembang-P. Balai Km 29, PO BOX: 1127, Palembang 30001 \\ E-mail: jamin.sbw@gmail.com
}

Tgl diterima: 12 Juli 2020; Tgl disetujui: 26 Januari 2021; Tgl direvisi: 1 Februari 2021

\begin{abstract}
Rubber clones have different adaptability which leads to no rubber clone being superior for all planting locations. Therefore, the agro-climatic characteristics of plantation area are needed to determine the suitability class of the land before extensive rubber planting is carried out. The aim of this study was to examine the growth of combination of clones (IRR 112 and IRR 118) and the number of umbrella leaves (two umbrellas and three umbrellas) during immature plants (TBM). Plantation was established at the Experimental Garden of the Rubber Research Center, Banyuasin Regency, South Sumatra Province. Land suitability was determined based on soil data and climate data. Clone growth was observed based on the growth of stems from a sampling of 500 trees for each clone-umbrella combination. Growth measurement was carried out every year until five years old plants. The results showed that IRR 112 clone rubber with three umbrellas was the best rubber planting material and reach $81 \%$ mature tapping stems after five years old. It is recommended that IRR 112 clone rubber with three umbrellas can be planted on land with the land suitability class suitable (S2) in the lowlands on Ultisol soil type.
\end{abstract}

Keywords: Clone, rubber seeds, land suitability, circumference of the stem

\begin{abstract}
ABSTRAK
Klon tanaman karet memiliki daya adaptasi yang berbeda-beda, sehingga tidak ada klon karet yang unggul di semua lokasi penanaman. Oleh karena itu karakteristik agroklimat pada areal penanaman tanaman karet diperlukan untuk menentukan kelas kesesuaian lahannya sebelum penanaman karet secara luas dilaksanakan. Penelitian bertujuan untuk menguji pertumbuhan kombinasi klon (IRR 112 dan IRR 118) dan jumlah payung daun bibit karet (payung dua dan payung tiga) selama masa tanaman belum menghasilkan (TBM). Penanaman dilakukan di Kebun Percobaan Pusat Penelitian Karet, Kabupaten Banyuasin, Provinsi Sumatera Selatan. Penentuan kelas kesesuaian lahan dilakukan berdasarkan data tanah dan data iklim. Pertumbuhan klon diamati berdasarkan pengukuran lilit batang pada 500 pohon sampling untuk setiap kombinasi klon-jumlah payung. Pengukuran pertumbuhan dilakukan setiap tahun sampai dengan umur lima tahun. Hasil penelitian menunjukkan bahwa bibit karet klon IRR 112 dengan jumlah payung tiga merupakan bibit karet yang terbaik dan pada umur lima tahun telah menghasilkan $81 \%$ batang matang sadap. Bibit karet tersebut dianjurkan ditanam pada lahan dengan kelas kesesuaian lahan sesuai (S2) di dataran rendah pada jenis tanah Ultisol.
\end{abstract}

Kata kunci: Klon, bibit karet, kesesuaian lahan, lilit batang 


\section{PENDAHULUAN}

Klon tanaman karet memiliki daya adaptasi yang berbeda-beda, sehingga setiap klon akan memiliki perbedaan dalam pertumbuhan dan produktivitasnya. Beberapa klon unggul memiliki daya adaptasi luas dan stabil, tetapi banyak juga klon memiliki respon spesifik pada lingkungan tertentu dan tidak ada klon karet yang unggul di semua lokasi penanaman (Aidi-Daslin, 2011; Budiningsih \& Effendi, 2012; Sayurandi, Suhendry, \& Pasaribu, 2014). Rendahnya produksi karet diakibatkan oleh adanya pengaruh faktor lingkungan biologi, agroklimat dan manajemen tanaman (Aidi-Daslin, 2011; 2014). Oleh karena itu, perlu diketahui karakteristik agroklimat areal penanaman tanaman karet untuk menentukan kelas kesesuaian lahannya sebelum dilakukan penanaman tanaman karet secara luas.

Penggunaan bahan tanam karet yang baik merupakan faktor penentu pencapaian produktivitas yang optimal (Boerhendhy, 2013; Boerhendhy \& Amypalupy, 2011; Siagian). Bibit unggul karet diperbanyak secara vegetatif dengan teknik okulasi melalui penempelan mata entres dari satu tanaman ke tanaman sejenis dengan tujuan mendapatkan sifat yang unggul (Amypalupy, 2012). Keuntungan perbanyakan tanaman secara vegetatif, yaitu sifat genetik tetuanya diturunkan sempurna (Junaidi, Atminingsih, \& Siagian, 2014). Keuntungan lainnya antara lain: pelaksanaannya mudah, persentase keberhasilan tinggi, dan efisien dalam penggunaan mata entres, karena satu batang entres dapat menghasilkan beberapa bahan tanam (Junaidi Atminingsih, \& Siagian, 2014).

Menurut Siagian \& Bukit (2015) hingga saat ini perbanyakan bibit karet unggul khususnya di tingkat penangkar dilakukan dengan sistem pembibitan di lapangan (ground nursery) dengan menggunakan teknik okulasi cokelat (brown budding). Hasil dari teknik ini adalah bibit stump mata tidur atau bibit dalam polybag. Penyediaan bibit dengan teknik okulasi cokelat memerlukan waktu 12-18 bulan mulai dari perkecambahan hingga bibit siap disalurkan, sedangkan teknik okulasi hijau memerlukan waktu selama 8-11 bulan (Boerhendhy, 2013). Berbagai upaya telah dilakukan untuk memperpendek waktu pengadaan bibit dalam jumlah banyak melalui teknik kultur jaringan dan micro cutting. Salah satu alternatif yang dapat dikembangkan untuk memenuhi kebutuhan bibit karet dalam jumlah banyak dan dalam waktu relatif singkat adalah sistem tanam benih langsung (tabela) di dalam polybag melalui teknik okulasi dini dengan umur batang bawah 2-3 bulan dan okulasi hijau dengan umur batang bawah 4-6 bulan (Boerhendhy, 2013). Pengadaan bibit dengan teknik okulasi dini lebih cepat dibandingkan dengan teknik okulasi cokelat (umur batang bawah > 6 bulan) maupun okulasi hijau (Hadi, Afifah, Prasetyo, \& Atmojo, 2012).

Saat ini bibit karet polybag yang ditanam di lapangan bervariasi jumlah payungnya, mulai dari satu payung tua sampai tiga payung tua. Payung daun pada bibit tanaman karet merupakan serangkaian daun yang telah membuka sempurna. Ukuran polybag $15 \mathrm{~cm}$ x $35 \mathrm{~cm}$ dianjurkan hanya untuk bibit 1-2 payung dan untuk ukuran polybag $25 \mathrm{~cm}$ x $40 \mathrm{~cm}$ untuk bibit 3-4 payung (Amypalupy, 2012). Penelitian ini bertujuan untuk mendapatkan klon dan jumlah payung daun bibit karet dengan pertumbuhan terbaik selama masa tanaman belum menghasilkan (TBM) di Kecamatan Sembawa, Kabupaten Banyuasin, Provinsi Sumatera Selatan.

\section{METODOLOGI}

\section{A. Lokasi dan Waktu Penelitian}

Penelitian dilakukan di Afdeling II Kebun Percobaan Pusat Penelitian Karet yang terletak di 2057'30"'-2 59'30" LS dan $104^{\circ} 28^{\prime} 45^{\prime \prime}-104^{\circ} 31^{\prime} 15^{\prime \prime}$ BT. Secara administrasi terletak di Desa Lalang Sembawa, Kecamatan Sembawa, Kabupaten Banyuasin, Provinsi Sumatera Selatan. Ketinggian tempat $\pm 10 \mathrm{~m}$ dari 
permukaan laut (m dpl). Topografi sebagian besar relatif datar dengan lereng antara 0$8 \%$. Jenis tanah termasuk dalam ordo Ultisol. Pengamatan dilakukan mulai tahun 2013 sampai dengan 2017.

\section{B. Prosedur Kerja}

\section{Penyiapan bibit}

Penyiapan bibit dilakukan dengan cara okulasi pada batang bawah karet di polybag. Polybag ukuran $25 \mathrm{~cm} \times 40 \mathrm{~cm}$ diisi dengan tanah top soil yang telah diayak dan dicampur dengan pupuk dasar RP (Rock Phosphate) sebanyak 50 gr per polybag. Pembibitan baik batang bawah maupun setelah okulasi tidak menggunakan naungan. Biji untuk batang bawah dikecambahkan 14 hari menggunakan klon GT1 (Gondang Tapen 1). Klon GT1 merupakan salah satu klon karet yang direkomendasikan untuk batang bawah (Boerhendhy \& Amypalupy, 2011). Kecambah tersebut ditanam dalam polybag. Pada umur 1-5 bulan diberi pupuk NPK majemuk (15:15:6-4) dengan frekuensi satu kali per bulan. Dosis pada bulan pertama 5 gr per polybag, selanjutnya pada bulanbulan berikutnya 7 gr per polybag sampai bibit siap tanam di lapangan (Boerhendhy, Agustina, \& Setiono, 2012).

Okulasi dilakukan secara okulasi hijau setelah batang bawah berumur 4-5 bulan (diameter batang bawah sekitar 6-8 $\mathrm{mm}$ ) menggunakan mata entres klon IRR 112 dan IRR 118 yang berasal dari ketiak daun. Klon IRR 112 dan IRR 118 merupakan klon dengan karakteristik pertumbuhan yang jagur (pertumbuhan cepat sekali) namun klon IRR 118 lebih baik pertumbuhannya apabila ditanam dengan curah hujan yang rendah $(<2.000 \mathrm{~mm} / \mathrm{th})$ (Sayurandi et al., 2014). Setelah okulasi berhasil kemudian dilakukan penyerongan $30-40 \mathrm{~cm}$ dari atas tanah. Penyerongan dilakukan 3-4 minggu setelah okulasi dan selanjutnya dipelihara dalam polybag sampai tanaman berpayung dua dan tiga. Proses okulasi sampai menjadi bibit siap tanam dapat dilihat pada Gambar 1 dan contoh bibit berpayung satu sampai tiga dapat dilihat pada Gambar 2. Pemeliharaan yang dilakukan antara lain pengendalian gulma, penyiraman, pengendalian penyakit daun, dan pemupukan. Bibit yang ditanam di lapang dengan kriteria panjang internude payung pertama minimal $25 \mathrm{~cm}$ dan diameter tunas $8 \mathrm{~mm}$.

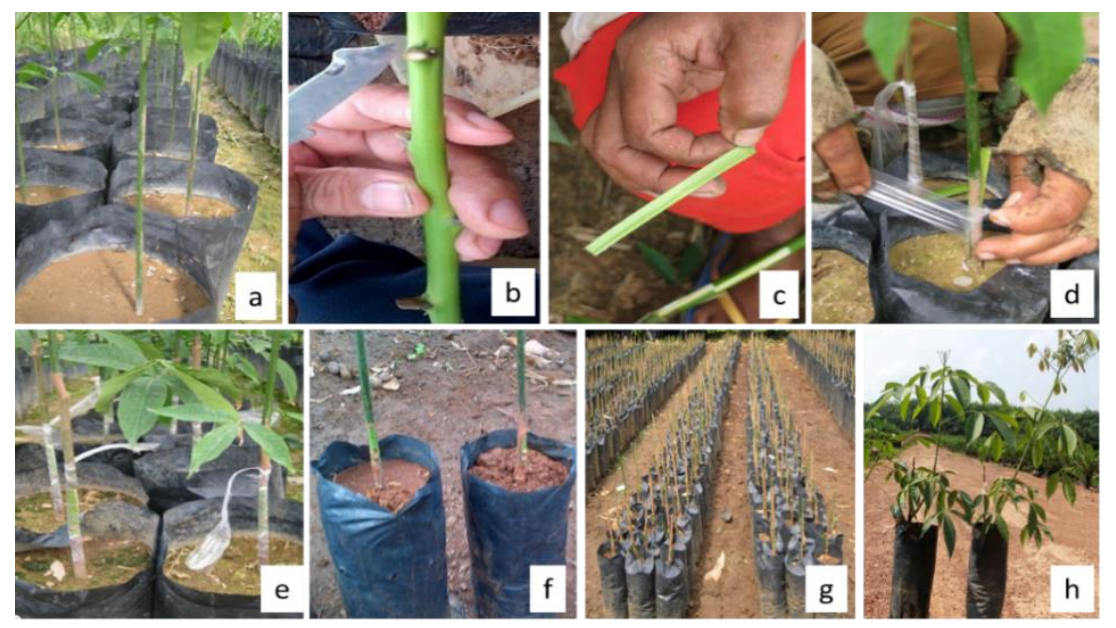

Gambar (Figure) 1. Proses okulasi bibit karet (Process of rubber budding) 

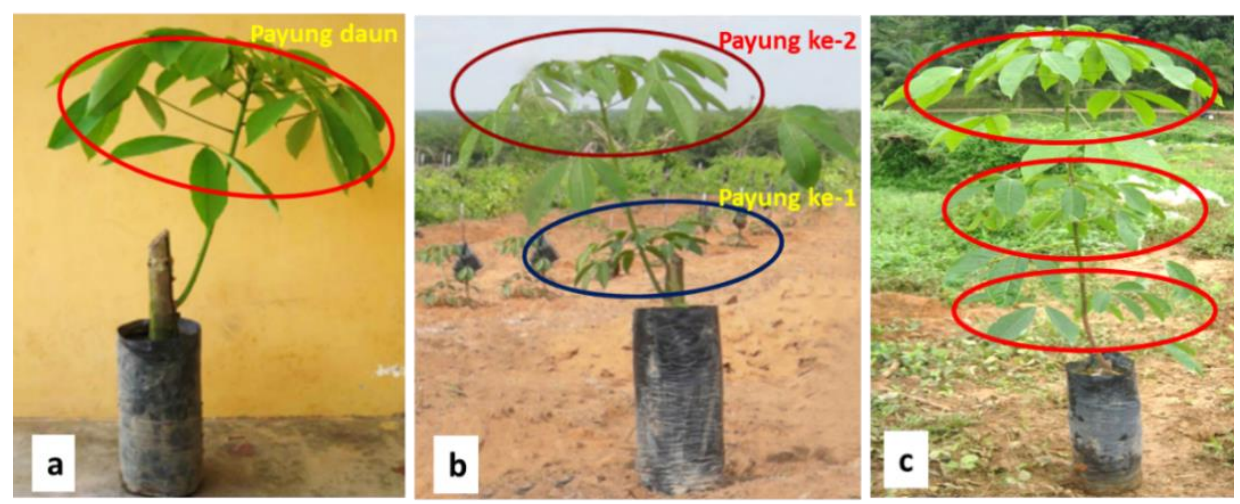

Gambar (Figure) 2. Bibit karet payung satu (a), payung dua (b) dan payung tiga (c) (Rubber planting material with one umbrella (a), two umbrellas $(b)$ and three umbrellas (c))

\begin{tabular}{|cccccccccc|}
\hline $\mathrm{V}$ & $\mathrm{V}$ & $\mathrm{V}$ & $\ldots$ & $\mathrm{V}$ & $\mathrm{W}$ & $\mathrm{W}$ & $\mathrm{W}$ & $\ldots$ & $\mathrm{W}$ \\
$\mathrm{V}$ & $\mathrm{V}$ & $\mathrm{V}$ & $\ldots$ & $\mathrm{V}$ & $\mathrm{W}$ & $\mathrm{W}$ & $\mathrm{W}$ & $\ldots$ & $\mathrm{W}$ \\
$\mathrm{V}$ & $\mathrm{V}$ & $\mathrm{V}$ & $\ldots$ & $\mathrm{V}$ & $\mathrm{W}$ & $\mathrm{W}$ & $\mathrm{W}$ & $\ldots$ & $\mathrm{W}$ \\
$:$ & $:$ & $:$ & & $:$ & $:$ & $:$ & $:$ & & $:$ \\
$:$ & $:$ & $:$ & & $:$ & $:$ & $:$ & $:$ & & $:$ \\
$\mathrm{V}$ & $\mathrm{V}$ & $\mathrm{V}$ & $\ldots$ & $\mathrm{V}$ & $\mathrm{W}$ & $\mathrm{W}$ & $\mathrm{W}$ & $\ldots$ & $\mathrm{W}$ \\
& & & & & & & & & \\
$\mathrm{X}$ & $\mathrm{X}$ & $\mathrm{X}$ & $\ldots$ & $\mathrm{X}$ & $\mathrm{Y}$ & $\mathrm{Y}$ & $\mathrm{Y}$ & $\ldots$ & $\mathrm{Y}$ \\
$\mathrm{X}$ & $\mathrm{X}$ & $\mathrm{X}$ & $\ldots$ & $\mathrm{X}$ & $\mathrm{Y}$ & $\mathrm{Y}$ & $\mathrm{Y}$ & $\ldots$. & $\mathrm{Y}$ \\
$\mathrm{X}$ & $\mathrm{X}$ & $\mathrm{X}$ & $\ldots$ & $\mathrm{X}$ & $\mathrm{Y}$ & $\mathrm{Y}$ & $\mathrm{Y}$ & $\ldots$ & $\mathrm{Y}$ \\
$:$ & $:$ & $:$ & & $:$ & $:$ & $:$ & $:$ & & $:$ \\
$:$ & $:$ & $:$ & & $:$ & $:$ & $:$ & $:$ & & $:$ \\
$\mathrm{X}$ & $\mathrm{X}$ & $\mathrm{X}$ & $\ldots$ & $\mathrm{X}$ & $\mathrm{Y}$ & $\mathrm{Y}$ & $\mathrm{Y}$ & $\ldots$ & $\mathrm{Y}$ \\
\hline
\end{tabular}

Keterangan (Remarks): $\mathrm{V}=$ Klon IRR 112 payung tiga (Clone of IRR 112 with three umbrellas), $\mathrm{W}=\mathrm{Klon}$ IRR 112 payung dua (Clone of IRR 112 with two umbrellas), X = Klon IRR 118 payung tiga (clone of IRR 118 with three umbrellas ), $\mathrm{Y}=\mathrm{Klon}$ IRR 118 payung dua (clone of IRR 118 with two umbrellas )

Gambar (Figure) 3. Plot penelitian tanaman karet (Rubber plant research plot)

\section{Penanaman}

Bibit karet ditanam dalam satu hamparan yang sama sesuai dengan masingmasing klon dan jumlah payung. Total luas tanaman karet 12 ha, yaitu 6 ha klon IRR 112 (3 ha asal bibit okulasi payung dua dan 3 ha asal bibit okulasi payung tiga) dan 6 ha klon IRR 118 (3 ha asal bibit okulasi payung dua dan 3 ha asal bibit okulasi payung tiga) (Gambar 3). Jarak tanam $3 \mathrm{~cm}$ x $6 \mathrm{~m}$, sehingga jumlah tanaman per ha adalah 550 batang. Ukuran lubang tanam $50 \mathrm{~cm}$ x $50 \mathrm{x}$ $60 \mathrm{~cm}$. Setiap lubang tanam diberi pupuk dasar Rock Phosphate sebanyak 250 gr/lubang. Selain itu juga diberikan belerang cirus (80 mesh) sebanyak 100 gr/lubang untuk mencegah penyakit jamur akar putih (JAP). 


\section{Pemeliharaan tanaman}

Pemeliharan tanaman dilakukan sesuai dengan standar umum. Pupuk anorganik yang digunakan adalah pupuk tunggal Urea, TSP, $\mathrm{KCl}$, dan Kieserit dengan kandungan hara masing-masing $46 \% \mathrm{~N}, 46 \% \quad \mathrm{P}_{2} \mathrm{O}_{5}$, $60 \% \mathrm{~K}_{2} \mathrm{O}$ dan $26 \% \mathrm{MgO}$. Dosis pemupukan pada tahun pertama sesuai dengan dosis umum (Wijaya \& Hidayati, 2012) dan selanjutnya sampai umur lima tahun menggunakan dosis pemupukan berdasarkan analisis kandungan hara tanah dan tanaman (Tabel 1). Aplikasi pupuk anorganik dilakukan sebanyak empat kali per tahun. Kegiatan pemeliharaan lainnya, yaitu penyiangan gulma dilakukan empat kali setahun sampai umur tanaman lima tahun setelah tanam.

\section{Metode}

\section{Pengumpulan data}

Data primer yang diambil untuk penentuan kesesuaian tanah meliputi elevasi, kemiringan lahan, persentase batuan di permukaan, kedalaman efektif, drainase, dan lapisan sulfat masam. Analisis laboratorium dilakukan untuk mendapatkan data $\mathrm{pH}$ dan tekstur tanah. Data sekunder yang digunakan untuk penentuan kesesuaian iklim meliputi curah hujan, jumlah bulan kering, dan suhu udara.

Data klimatologi diperoleh dari stasiun klimatologi Pusat Penelitian Karet. Data curah hujan diamati menggunakan alat penakar curah hujan tipe observatorium dan suhu udara menggunakan alat termometer. Pengamatan curah hujan dilakukan setiap hari pada pukul 7.00 WIB dengan cara mengukur volume air yang tertampung pada alat dengan menggunakan gelas ukur.

Data kondisi perkembangan lilit (keliling) batang karet diukur pada tinggian $100 \mathrm{~cm}$ dari batas tautan okulasi menggunakan meteran (Sahuri, 2020). Pengambilan data dilakukan dengan cara sampling sebanyak 500 pohon di setiap populasi tanaman karet, yaitu pada populasi tanaman karet yang berasal dari klon IRR
112 dan IRR 118 dengan asal bibit okulasi payung dua dan tiga. Pengukuran lilit batang karet dilakukan setahun sekali sampai umur tanaman lima tahun (60 bulan) pada pohon contoh yang sama. Selanjutnya data sampling tersebut dianalisis dengan Uji-T Student dari keempat populasi tersebut.

\section{Pengolahan dan analisis data}

Kelas kesesuaian lahan untuk tanaman karet diperoleh dari penggabungan antara kelas kesesuian tanah dan iklim. Penilaian kelas kesesuaian tanah dibuat menggunakan sistem yang dibuat oleh Sugiyanto, Sihombing, \& Darmandono (1998) dan Wijaya (2008). Penilaian kelas kesesuaian iklim menggunakan sistem yang dibuat oleh Wijaya (1996). Parameter tanah dan iklim yang digunakan disajikan pada Tabel 2 dan Tabel 3. Kesesuaian tanah dikelompokkan menjadi S1, S2, S3, dan TS dengan kriteria; $\mathrm{S} 1$ (sangat sesuai) dengan maksimum 1 faktor pembatas medium, S2 (sesuai) dengan maksimum 2 faktor pembatas medium, S3 (kurang sesuai) dengan 2 atau lebih faktor pembatas medium dan 1 faktor pembatas berat yang masih bisa diperbaiki, TS (tidak sesuai) dengan 2 atau lebih faktor pembatas berat (Wijaya, 2008).

Data hasil pengukuran lilit batang kemudian dianalisis statistik menggunakan uji-t student antara pertumbuhan asal bibit dua payung daun dengan asal bibit tiga payung daun pada masing-masing klon untuk melihat pengaruh jumlah payung daun terhadap pertumbuhan. Selanjutnya dari data pertumbuhan lilit batang setiap tahun dilihat pertambahan lilit batang setiap tahun untuk melihat pertambahan lilit batang masing-masing klon. Selain itu, pada umur tertentu dilakukan penentuan matang sadap kebun yang berarti kebun karet tersebut telah siap dilakukan penyadapan. Syarat matang sadap kebun adalah persentase tanaman yang telah mencapai lilit batang di atas $45 \mathrm{~cm}$ dengan jumlah batang minimal $60 \%$ dari total populasi (Kuswanhadi \& Herlinawati, 2018). 
Tabel (Table) 1. Dosis pemupukan pada tiap klon (Fertilization dosage for each clone)

\begin{tabular}{|c|c|c|c|c|c|}
\hline \multirow[t]{2}{*}{ TBM } & \multirow[t]{2}{*}{ Klon (Clone) } & \multicolumn{4}{|c|}{$\begin{array}{c}\text { Dosis rekomendasi (gram/pohon/tahun) (Dose recommendation } \\
(\text { gram/tree/year }))^{*}\end{array}$} \\
\hline & & Urea & TSP & $\mathrm{KCl}$ & Kieserit \\
\hline 1 & $\begin{array}{l}\text { IRR } 112 \\
\text { IRR } 118\end{array}$ & 250 & 120 & 100 & 50 \\
\hline \multirow[t]{2}{*}{2} & IRR 112 & 300 & 200 & 320 & 50 \\
\hline & IRR 118 & 310 & 230 & 320 & 90 \\
\hline \multirow[t]{2}{*}{3} & IRR 112 & 300 & 200 & 350 & 50 \\
\hline & IRR 118 & 320 & 200 & 320 & 90 \\
\hline \multirow[t]{2}{*}{4} & IRR 112 & 340 & 230 & 320 & 120 \\
\hline & IRR 118 & 310 & 230 & 320 & 130 \\
\hline \multirow[t]{2}{*}{5} & IRR 112 & 350 & 240 & 350 & 100 \\
\hline & IRR 118 & 320 & 240 & 300 & 120 \\
\hline
\end{tabular}

Keterangan (Remark) : *Dosis rekomendasi dihitung berdasarkan rumus perhitungan kebutuhan pupuk untuk tanaman karet (The recommended dosage is calculated based on the calculation formula for the rubber plants' need for fertilizer) (Adiwiganda et al., 1994)

Tabel (Table) 2. Kriteria kesesuaian tanah untuk tanaman karet (Soil suitability criteria for rubber plants)

\begin{tabular}{|c|c|c|c|}
\hline \multirow{2}{*}{ Parameter (Parameter) } & \multicolumn{3}{|c|}{ Level faktor pembatas (Limiting factor level) } \\
\hline & Ringan (Mild) & Medium (Medium) & Berat (Heavy) \\
\hline Topografi (Topography)* & $0-8^{0}$ & $8-15^{0}$ & $>15^{0}$ \\
\hline $\begin{array}{l}\text { Batu dipermukaan (Stones on the } \\
\text { surface) }(\%)^{*}\end{array}$ & 0 & $0-50$ & $>50$ \\
\hline Kedalaman efektif (Effective depth) $(\mathrm{cm})$ & $>100$ & $45-100$ & $<45$ \\
\hline Lapisan gambut (Peat layer) $(\mathrm{cm})^{*}$ & $0-25$ & $25-50$ & $>50$ \\
\hline $\begin{array}{l}\text { Lapisan sulfat masam (Sulfuric acid } \\
\text { layer) }\end{array}$ & - & $\begin{array}{c}50 \mathrm{~cm} \text { dari } \\
\text { Permukaan (From } \\
\text { the surface) }\end{array}$ & $\begin{array}{c}25 \mathrm{~cm} \text { dari permukaan (From } \\
\text { the surface) }\end{array}$ \\
\hline Drainase (Drainage) & $\begin{array}{l}\text { Medium } \\
\text { (Medium) }\end{array}$ & $\begin{array}{c}\text { Cepat/lambat } \\
(\text { Fast/slow })\end{array}$ & $\begin{array}{l}\text { Sangat cepat/sangat lambat } \\
\text { (Very fast/very slow) }\end{array}$ \\
\hline $\begin{array}{l}\text { Tekstur tanah } \\
\text { (Soil texture) }\end{array}$ & $\begin{array}{c}\text { Liat (Clay) } \\
10-40 \% \\
\text { Debu (Dust) } \\
20-50 \% \\
\text { Pasir (Sand) } \\
20-50 \%\end{array}$ & $\begin{array}{c}\text { Pasir/debu } 50-80 \% \\
\text { dengan liat } 10-30 \% \\
\text { (Sand /dust } 50- \\
80 \% \text { with } 10-30 \% \\
\text { clay) } \\
\text { Pasir/debu } 0-20 \% \\
\text { dengan liat } 40-80 \% \\
\text { (Sand /dust 0-20\% } \\
\text { with 40-80\% clay) }\end{array}$ & $\begin{array}{l}\text { Liat }>80 \% \text { atau Pasir }>80 \% \\
(\text { Clay }>80 \% \text { or Sand }>80 \%)\end{array}$ \\
\hline $\begin{array}{l}\text { Keasaman tanah }(\mathrm{pH}) \\
\text { (Soil acidity) }\end{array}$ & $4,0-5,5$ & $5,6-6,5$ & $<4,0$ atau $>6,5$ \\
\hline
\end{tabular}

Sumber (Source) : Sugiyanto, Sihombing, \& Darmandono (1998); *Watson (1989) 
Tabel (Table) 3. Kriteria kesesuaian iklim untuk tanaman karet (Climate suitability criteria for rubber plants)

\begin{tabular}{|c|c|c|c|c|c|}
\hline $\begin{array}{l}\text { Tipe hujan } \\
\text { (Rain type) }\end{array}$ & $\begin{array}{l}\text { Curah hujan } \\
\text { (Rainfall) } \\
\text { (mm/tahun) }\end{array}$ & $\begin{array}{l}\text { Jumlah } \\
\text { bulan kering } \\
\text { (Number of } \\
\text { dry months) }\end{array}$ & $\begin{array}{c}\text { Suhu udara } \\
\text { (Temperature) } \\
\left({ }^{\circ} \mathrm{C}\right)\end{array}$ & Faktor pembatas (Limiting factor) & $\begin{array}{l}\text { Kelas } \\
\text { kesesuaian } \\
\text { (Suitability } \\
\text { class) }\end{array}$ \\
\hline $\begin{array}{c}\text { Sedang } \\
\text { (Moderate) }\end{array}$ & $1.500-3.000$ & $0-2$ & $25-28$ & - & S1 \\
\hline $\begin{array}{l}\text { Kering } \\
(\text { Dry })\end{array}$ & $1.500-3.000$ & $3-4$ & $25-28$ & $\begin{array}{l}\text { Stress air moderat } \\
\text { (Moderate water stress) }\end{array}$ & S2 \\
\hline \multirow[t]{4}{*}{$\begin{array}{l}\text { Basah } \\
(W e t)\end{array}$} & $3.000-4.000$ & 0 & $25-28$ & $\begin{array}{l}\text { Kelembaban tinggi, penyakit gugur } \\
\text { daun Colletotrichum, gangguan } \\
\text { penyadapan } \\
\text { (High humidity, Colletotrichum } \\
\text { disease, day tapping) }\end{array}$ & S3 \\
\hline & \multirow[t]{2}{*}{ - } & $>4$ & & $\begin{array}{l}\text { Stress air berat } \\
\text { (Heavy water stress) }\end{array}$ & TS \\
\hline & & - & $<25$ & $\begin{array}{l}\text { Suhu rendah menghambat } \\
\text { pertumbuhan } \\
\text { (Low temperatures inhibit growth) }\end{array}$ & TS \\
\hline & $>4.000$ & 0 & $25-28$ & $\begin{array}{l}\text { Curah hujan berlebihan, gangguan } \\
\text { penyadapan, penyakit gugur daun } \\
\text { (Excessive rainfall, tapping } \\
\text { disorders, leaffall disease) }\end{array}$ & TS \\
\hline
\end{tabular}

Sumber (Source) : Wijaya (1996)

Keterangan (Remark): S1 (Sangat sesuai/Very suitable), S2 (Cukup sesuai/Suitable), S3 (Kurang sesuai/Less suitable), TS (Tidak sesuai/Not suitable)

\section{Hasil dan Pembahasan}

\section{A. Hasil}

Penentuan kesesuaian lahan untuk tanaman karet menggunakan data pengamatan di lapangan dan analisis di laboratorium disajikan pada Tabel 4. Data iklim yang digunakan mulai tahun 20082017 (sepuluh tahun terakhir), dengan ratarata curah hujan $2.695 \mathrm{~mm} /$ tahun, bulan kering rata-rata tiga bulan/tahun dan suhu udara $28^{\circ} \mathrm{C}$. Grafik curah hujan rata-rata bulanan tahun 2008-2017 disajikan pada Gambar 4.

Besarnya tanaman karet masingmasing klon sampai dengan umur lima tahun dapat dilihat pada Tabel 5. Dari data pertumbuhan pada Tabel 5, bahwa pada umur satu tahun, lilit batang klon IRR 112 asal bibit payung tiga paling tinggi. Pada umur dua tahun klon IRR 112 asal bibit payung dua mampu menyamai pertumbuhan klon IRR 112 yang berpayung tiga, dan tahun ketiga menyusul klon IRR 118 asal bibit payung tiga menyamai klon IRR 112 asal bibit payung dua dan tiga. Pada umur empat tahun, lilit batang klon IRR 112 asal bibit payung dua dan tiga sama dan berbeda dengan IRR 118, namun pada umur lima tahun besarnya lilit batang karet antara klon IRR 112 asal bibit payung dua dan tiga dengan klon IRR 118 asal bibit payung tiga tidak berbeda nyata. Dengan demikian, klon IRR 112 bisa dibuat bibit dengan payung dua atau tiga, sedangkan klon IRR 118 berpayung tiga. Ketiga asal bibit tersebut berpotensi untuk dikembangkan dalam penanaman karet di daerah dengan karakteristik tanah datarbergelombang, kedalaman efektif $>100$ $\mathrm{cm}$, drainase medium, $\mathrm{pH}$ 4-5, tekstur lempung, dan iklim dengan curah hujan 2.500-3.000 $\mathrm{mm} / \mathrm{th}$, tiga bulan kering, suhu rata-rata $28^{\circ} \mathrm{C}$. 
Tabel (Table) 4. Hasil pengamatan di lapangan dan analisis di laboratorium (The results of observations in the field and analysis in the laboratory)

\begin{tabular}{|c|c|c|}
\hline Parameter (Parameter) & $\begin{array}{l}\text { Kondisi lapang } \\
\text { (Field conditions) }\end{array}$ & $\begin{array}{l}\text { Faktor pembatas } \\
\text { (Limiting factor) }\end{array}$ \\
\hline Elevasi (Elevation) & 20-30 m dpl & Ringan (Mild) \\
\hline Kelerengan (Slope) & $5-8^{\circ}$ & Ringan (Mild) \\
\hline $\begin{array}{l}\text { Batu dipermukaan } \\
\text { (Stones on the surface) }(\%)\end{array}$ & $0 \%$ & Ringan (Mild) \\
\hline $\begin{array}{l}\text { Kedalaman efektif } \\
\text { (Effective depth) }\end{array}$ & $>100 \mathrm{~cm}$ & Ringan (Mild) \\
\hline Drainase (Drainage) & Medium (Medium) & Ringan (Mild) \\
\hline $\begin{array}{l}\text { Lapisan sulfat masam } \\
\text { (Sulfuric acid layer) }\end{array}$ & 0 & Ringan (Mild) \\
\hline $\mathrm{pH}$ tanah $($ Soil $\mathrm{pH})$ & 4,51 & Ringan (Mild) \\
\hline $\begin{array}{l}\text { Tekstur } \\
\text { (Texture) }\end{array}$ & $\begin{array}{c}\text { Lempung (Loam) } \\
\text { Pasir 25\%, Debu 43\%, } \\
\text { Liat 32\% (Sand 25\%, Dust } 43 \% \text {, Clay } \\
32 \%)\end{array}$ & Ringan $($ Mild $)$ \\
\hline
\end{tabular}

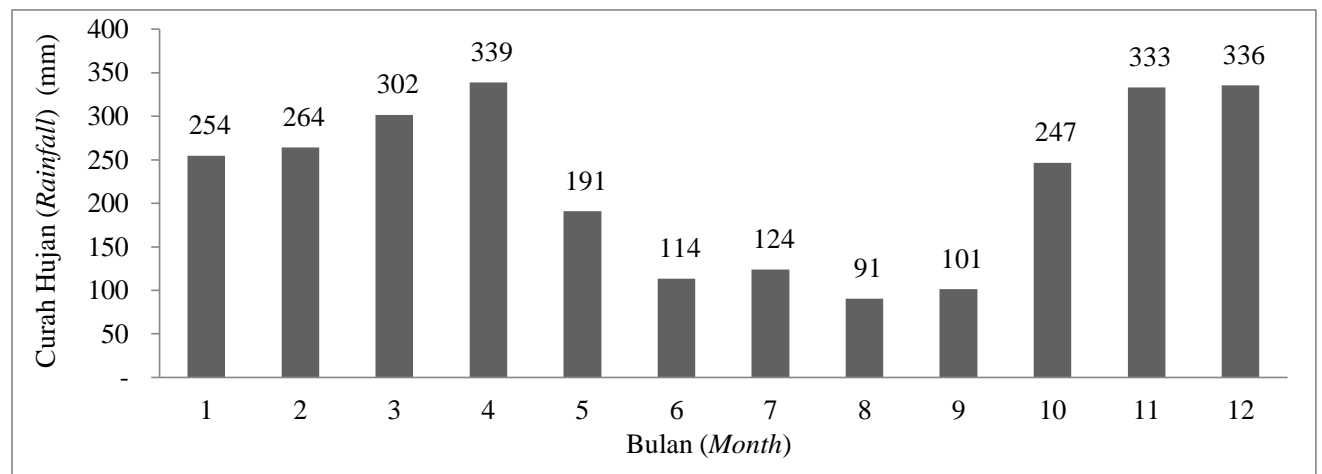

Gambar (Figure) 4. Grafik rata-rata curah hujan bulanan (mm) tahun 2008-2017 (Graph of the average monthly rainfall $(\mathrm{mm})$ of the year 2008-2017)

Tabel (Table) 5. Pertumbuhan lilit batang tanaman $(\mathrm{cm})$ pada umur satu tahun sampai lima tahun (plant growth from one year to five years)

\begin{tabular}{ccccccc}
\hline \multirow{2}{*}{$\begin{array}{c}\text { Klon } \\
\text { Clone })\end{array}$} & Payung & (Whorl) & \multicolumn{5}{c}{ Umur (Age) (Tahun/Year) } \\
\cline { 3 - 7 } IRR 112 & Dua (Two) & $10,9 \pm 1,7 \mathrm{a}$ & $22,6 \pm 3,3 \mathrm{~b}$ & $32,1 \pm 2,4 \mathrm{~b}$ & $40,0 \pm 5,6 \mathrm{~b}$ & $47,8 \pm 5,6 \mathrm{~b}$ \\
IRR 112 & Tiga (Three) & $12,2 \pm 1,8 \mathrm{~b}$ & $24,6 \pm 2,4 \mathrm{~b}$ & $34,8 \pm 1,6 \mathrm{~b}$ & $43,3 \pm 2,8 \mathrm{~b}$ & $49,4 \pm 3,5 \mathrm{~b}$ \\
IRR 118 & Dua (Two) & $9,1 \pm 1,4 \mathrm{a}$ & $18,7 \pm 2,3 \mathrm{a}$ & $31,7 \pm 1,8 \mathrm{a}$ & $37,4 \pm 6,1 \mathrm{a}$ & $41,9 \pm 5,7 \mathrm{a}$ \\
IRR 118 & Tiga (Three) & $10,5 \pm 1,4 \mathrm{a}$ & $21,4 \pm 2,5 \mathrm{a}$ & $32,5 \pm 1,7 \mathrm{~b}$ & $38,6 \pm 4,2 \mathrm{a}$ & $45,3 \pm 4,2 \mathrm{~b}$ \\
\hline
\end{tabular}

Keterangan (Remark): Angka rata-rata pada kolom yang sama yang diikuti oleh huruf yang sama tidak berbeda nyata pada taraf uji t 5\% (Means in the same column followed by the same letters were not significantly different based on t test at $p=0,05$ ) 
Tabel (Table) 6. Tabel pertambahan lilit batang masing-masing klon (Table of the stem circumference increment of each clone)

\begin{tabular}{llccccc}
\hline \multirow{2}{*}{ Klon (Clone) } & Payung (Whorl) & \multicolumn{5}{c}{ Umur (Age) (Tahun/Year) } \\
\cline { 3 - 7 } IRR 112 & Dua (Two) & 1 & 2 & 3 & 4 & 5 \\
IRR 112 & Tiga (Three) & $12,9 \pm 1,7 \mathrm{a}$ & $11,7 \pm 2,2 \mathrm{~b}$ & $9,5 \pm 3,9$ a & $7,9 \pm 6,0 \mathrm{~b}$ & $7,8 \pm 4,3 \mathrm{~b}$ \\
IRR 118 & Dua (Two) & $9,1 \pm 1,4 \mathrm{a}$ & $9,6 \pm 2,2 \mathrm{a}$ & $13,0 \pm 2,7 \mathrm{~b}$ & $5,7 \pm 5,8 \mathrm{a}$ & $4,5 \pm 1,0 \mathrm{a}$ \\
IRR 118 & Tiga (Three) & $10,5 \pm 1,4 \mathrm{a}$ & $10,9 \pm 2,3 \mathrm{a}$ & $11,1 \pm 2,8 \mathrm{~b}$ & $6,1 \pm 4,4 \mathrm{a}$ & $6,7 \pm 2,2 \mathrm{~b}$ \\
\hline
\end{tabular}

Keterangan (Remark): Angka rata-rata pada kolom yang sama yang diikuti oleh huruf yang sama tidak berbeda nyata pada taraf uji t 5\% (Means in the same column followed by the same letters were not significantly different based on t test at $p=0,05$ )

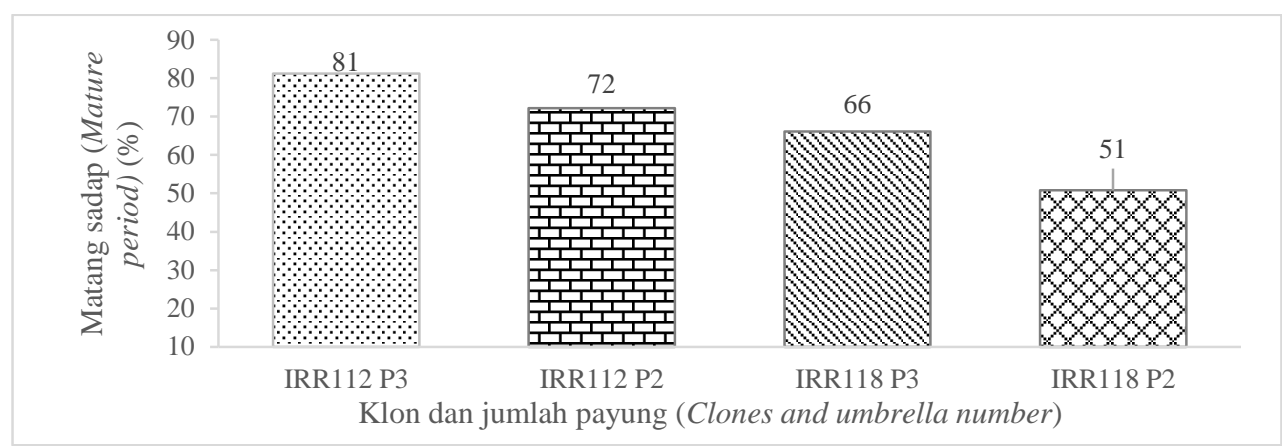

Gambar (Figure) 6. Persentase matang sadap pada umur lima tahun (Percentage of mature period at the age of five years)

Pertambahan pertumbuhan masingmasing klon disajikan pada Tabel 6. Secara umum pertambahan lilit batang sampai dengan umur tiga tahun mencapai 9,1-13 $\mathrm{cm} /$ tahun. Pada tahun keempat dan kelima pertumbuhannya mengalami penurunan yang hanya berkisar 4,5-8,5 cm/tahun. Klon IRR 112 asal bibit tiga payung daun mengalami pertambahan lilit batang paling tinggi pada tahun kedua, yakni sebesar 12,4 cm/tahun, sedangkan klon IRR 118 asal bibit dua payung daun mengalami pertambahan lilit batang pada tahun ketiga sebesar $13 \mathrm{~cm} /$ tahun. Klon IRR 112 asal bibit payung tiga pada tahun pertama paling tinggi pertambahan lilit batangnya dan pada tahun kedua tidak berbeda dengan klon IRR 112 asal bibit payung dua. Pada tahun ketiga pertambahan lilit batang berbeda antara klon IRR 112 dan IRR 118, namun pertambahan lilit batang klon IRR 118 lebih tinggi. Pada tahun keempat berbeda antara klon IRR 112 dan IRR 118, namun pertambahan lilit batang klon IRR 112 lebih tinggi. Pada tahun kelima pertambahan lilit batang antara klon IRR 112 asal bibit payung dua dan tiga dengan klon IRR 118 asal bibit payung tiga tidak berbeda nyata, namun berbeda nyata dengan klon IRR 118 asal bibit payung dua.

Persentase matang sadap kebun masing-masing klon pada umur lima tahun disajikan pada Gambar 6. Klon IRR 112 asal bibit tiga payung telah mencapai $81 \%$ dan $72 \%$ asal bibit dua payung, sedangkan klon IRR 118 baru mencapai 66\% (asal bibit tiga payung) dan $51 \%$ (asal bibit dua payung).

\section{B. Pembahasan}

Kelas kesesuaian tanah berdasarkan pengamatan parameter tanah di lokasi penelitian (Tabel 4) termasuk kelas S1 karena semua parameter termasuk faktor pembatas yang ringan. Kelas kesesuaian iklim di lokasi penelitian berdasarkan data iklim 10 tahun termasuk dalam kelas S2, dengan faktor pembatas rata-rata bulan kering tiga bulan/tahun. Berdasarkan kelas 
kesesuaian tanah yang termasuk $\mathrm{S} 1$ dan kelas kesesuaian iklim termasuk $\mathrm{S} 2$, maka kelas kesesuaian lahan pada lokasi penelitian termasuk kelas S2.

Berdasarkan data pertumbuhan Tabel 5 pada umur lima tahun telah mencapai lilit batang lebih dari $45 \mathrm{~cm}$ yang berarti telah siap untuk dilakukan penyadapan, kecuali klon IRR 118 asal bibit dua payung daun. Klon IRR 118 asal bibit dua payung daun pada umur lima tahun belum siap disadap karena menurut Kuswanhadi \& Herlinawati (2018) persyaratan tanaman karet bisa dilakukan penyadapan ukuran lilit batangnya minimal $45 \mathrm{~cm}$.

Hasil uji-t antar klon dan asal bibit okulasi jumlah payung pada Tabel 5 menunjukkan bahwa pada tahun pertama klon IRR 112 payung tiga berbeda nyata dengan perlakuan lainnya. Pada tahun kedua klon IRR 112 payung tiga tidak berbeda nyata dengan klon IRR 112 payung dua dan berbeda nyata dengan klon IRR 118 payung dua maupun payung tiga. Pada tahun ketiga klon IRR 112 payung tiga, IRR 112 payung dua, dan IRR 118 payung tiga tidak berbeda nyata dan berbeda nyata dengan klon IRR 118 payung dua. Pada tahun keempat klon IRR 112 payung tiga tidak berbeda nyata dengan klon IRR 112 payung dua dan berbeda nyata dengan klon IRR 118 payung dua maupun payung tiga. Pada tahun kelima klon IRR 112 payung tiga, IRR 112 payung dua, dan IRR 118 payung tiga tidak berbeda nyata dan berbeda nyata dengan klon IRR 118 payung dua. Pertumbuhan yang konsisten paling tinggi dari tahun pertama sampai tahun kelima, adalah klon IRR 112 payung tiga, sementara klon IRR 112 payung dua pada tahun kedua sampai tahun kelima pertumbuhannya tidak berbeda nyata dengan klon IRR 112 payung tiga.

Pada umur lima tahun klon IRR 112 asal bibit dua dan tiga payung daun telah siap dilakukan penyadapan karena rata-rata lilit batang masing-masing telah mencapai $49,4 \mathrm{~cm}$ dan 47,8 cm. Klon IRR 118 pertumbuhannya lebih lambat dibandingkan dengan klon IRR 112 karena pada umur lima tahun asal bibit tiga payung daun ratarata lilit batangnya baru mencapai $45,3 \mathrm{~cm}$, sedangkan asal bibit dua payung daun pada umur lima tahun baru mencapai $41,9 \mathrm{~cm}$. Hasil penelitian ini menunjukkan hasil yang sama dengan penelitian Sayurandi et al. (2014) bahwa klon IRR 118 lebih rendah pertumbuhannya dibandingkan dengan klon IRR 112 pada lokasi dengan curah hujan yang lebih tinggi/basah. Hal tersebut menunjukkan bahwa karakteristik genetis klon IRR 118 lebih cocok ditanam di lokasi dengan curah hujan yang rendah $(<2.000$ $\mathrm{mm} /$ tahun) dibandingkan dengan klon IRR 112 (Aidi-Daslin, 2014). Selain itu juga faktor kesesuaian lahan juga mempengaruhi pertumbuhan masing-masing klon karet karena salah satu faktor penentu kesesuaian lahan adalah curah hujan (Saputra \& Stevanus, 2015).

Pertambahan lilit batang per tahun sejalan dengan pertumbuhan lilit batang tanaman, semakin tinggi pertumbuhan tanaman, maka pertambahan lilit batang per tahun juga akan semakin tinggi. Pertambahan lilit batang paling tinggi terjadi pada tahun kedua untuk klon IRR 112 dengan pertambahan paling tinggi 12,4 $\mathrm{cm} /$ tahun, sedangkan untuk klon IRR 118 terjadi pada tahun ketiga dengan pertambahan tinggi $13 \mathrm{~cm} /$ tahun. Hasil penelitian sebelumnya menunjukkan bahwa puncak pertumbuhan tanaman karet selama masa tanaman belum menghasilkan pada umur tiga tahun (Saputra, Ardika \& Wijaya, 2014; Saputra \& Stevanus, 2015). Rendahnya pertumbuhan klon IRR 112 pada tahun ketiga disebabkan oleh adanya kemarau panjang pada tahun ketiga (tahun 2015) dan untuk klon IRR 118 pertumbuhannya tidak terhambat karena klon IRR 118 lebih cocok di daerah dengan curah hujan yang lebih rendah (Sayurandi et al., 2014).

Persentase tanaman karet yang telah siap dilakukan penyadapan pada umur lima tahun (Gambar 6) menunjukkan bahwa klon IRR 118 asal bibit dua payung yang belum mencapai $60 \%$. Hal ini disebabkan oleh klon IRR 118 memiliki karakter klon yang 
pertumbuhannya lebih lambat dibandingkan klon IRR 112 untuk di daerah dengan curah hujan > $2.000 \mathrm{~mm} /$ tahun (Aidi-Daslin, 2014; Sayurandi et al., 2014).

\section{KESIMPULAN DAN SARAN}

\section{A. Kesimpulan}

Jumlah payung daun bibit karet yang ditanam di lahan dengan kelas kesesuaian lahan S2 (sesuai) untuk tanaman karet berpengaruh nyata terhadap pertumbuhan lilit batang, pertambahan lilit batang per tahun dan persentase matang sadap kebun. Klon IRR 112 pada umur lima tahun telah mencapai lilit batang rata-rata 49,4 cm (asal bibit tiga payung) dan $47,8 \mathrm{~cm}$ (asal bibit dua payung, lebih baik dibanding klon IRR 118 pada umur lima tahun yang telah mencapai lilit batang rata-rata 45,3 cm (asal bibit tiga payung) dan $41,9 \mathrm{~cm}$ (asal bibit dua payung).

\section{B. Saran}

Strategi untuk mempersingkat masa tanaman belum menghasilkan (TBM) pada lahan dengan kelas kesesuaian lahan S2 (sesuai) untuk tanaman karet salah satunya dengan cara menggunakan klon yang pertumbuhannya cepat seperti klon IRR 112 dengan material bibit tiga payung daun.

\section{UCAPAN TERIMA KASIH}

Penulis menyampaikan terima kasih kepada Kepala Pusat Penelitian Karet atas izin dan fasilitas yang diberikan, sehingga penelitian ini dapat dilaksanakan. Selain itu, penulis juga menyampaikan terima kasih kepada Bapak Island Boerhendhy atas bimbingannya selama penelitian; Achmadi dan M. Iqlal Fauzi sebagai teknisi yang membantu pengamatan di lapangan.

\section{DAFTAR PUSTAKA}

Adiwiganda, Y.T., Hardjono, A., Manurung, A., Sihotang, U.T.B.D., Sudiharto, Goenadi, D.H., \& Sihombing, H. (1994). Teknik penyusunan rekomendasi pemupukan tanaman karet. Forum Komunikasi Karet, 1-17.

Aidi-Daslin. (2011). Evaluasi pengujian lanjutan klon karet IRR seri 200 pada masa tanaman belum menghasilkan. Jurnal Penelitian Karet, 29(2), 93101.

Aidi-Daslin. (2014). Perkembangan penelitian klon karet unggul IRR seri 100 sebagai penghasil lateks dan kayu. Warta Perkaretan, 33(1), 1-10.

Alwi, N., \& Aidi-Daslin. (1990). Laporan mengenai pengujian klon pertukaran internasional 1974. Prosiding Lokakarya Nasional Pemuliaan Tanaman Karet 1990, 243-249.

Amypalupy, K. (2012). Pembuatan bahan tanam; saptabina usahatani karet rakyat dalam (Lasminingsih, M, Suryaningtyas, H, Nancy, C, \& Vachlepi, A. (eds.); VI). Balai Penelitian Sembawa, Pusat Penelitian Karet.

Boerhendhy, I., \& Amypalupy, K. (2011). Optimalisasi produktivitas karet melalui penggunaan bahan tanam, pemeliharaan, sistem eksploitasi, dan peremajaan tanaman. Jurnal Litbang Pertanian, 30(1), 23-30.

Boerhendhy, I., Agustina, D.S., \& Setiono. (2012). Paket teknologi karet untuk mempersingkat masa tanaman belum menghasilkan kurang dari empat tahun. Prosiding Konferensi Nasional Karet, 269-278.

Boerhendhy, I. (2013). Prospek perbanyakan bibit karet unggul dengan teknik okulasi dini. Jurnal Litbang Pertanian, 32(2), 85-90.

Budiningsih, K., \& Effendi, R. (2012). Analisis finansial hutan tanaman campuran meranti merah (Shorea spp.) dan karet rakyat (Hevea brasiliensis) di Hinas Kiri Kalimantan Selatan. Jurnal Penelitian Hutan Tanaman, 9(4), 233240.

Chanana, Y.R., \& Gill, M.I.S. (2008). General Horticulture Propagation and Nursery Management. Department 
of Horticulture. Punjab Agricultural University.

Hadi, H., Afifah, E., Prasetyo, N.E., \& Atmojo, L. (2012). Prospek teknik okulasi dini dalam penyediaan bibit karet klonal. Konferensi Nasional Karet 2012, 39-45.

Junaidi, Atminingsih, \& Siagian, N. (2014). Pengaruh jenis mata entres dan klon terhadap keberhasilan okulasi dan pertumbuhan tunas pada okulasi hijau di polibeg. Jurnal Penelitian Karet, 32(1), 21-30.

Kuswanhadi, \& Herlinawati, E. (2018). Penyadapan tanaman karet. Dalam Vachlepi, A, Sahuri, Ismawanto, S., Stevanus, C,T, \& Aji, M. (Eds.), Saptabina Usahatani Karet Rakyat (8th ed., p. 105). Balai Penelitian Sembawa, Pusat Penelitian Karet.

Sahuri. (2020). Peningkatan pertumbuhan dan hasil karet melalui sistem tumpang sari berbasis karet. Jurnal Penelitian Hutan Tanaman, 17(1), 27-40.

Saputra, J., Ardika, R., \& Wijaya, T. (2014). Pengaruh pupuk hayati mikoriza terhadap efisiensi pupuk anorganik pada tanaman karet (Hevea Brasiliensis). Dalam: Salah, E., Hower, H, Sasanti, A.D, Puspitahati, M.I., Syafutri, Yulisman, \& Yosi, F. (Eds.), Prosiding Seminar Nasional dalam Rangka Dies Natalis ke-51 Fakultas Pertanian UNSRI. Tema: Mewujudkan ketahanan pangan dalam menghadapi pasar bebas ASEAN. (pp. 237-244). Fakultas Pertanian UNSRI.

Saputra, J., \& Stevanus, C.T. (2015). Evaluasi pertumbuhan tanaman karet belum menghasilkan klon PB 260 pada daerah kelas kesesuaian iklim S1 dan S2. Prosiding Seminar Nasional Dies
Natalis Ke-52 Fakultas Pertanian Universitas Sriwijaya, 717-724.

Sayurandi, Suhendry, I., \& Pasaribu, S.A. (2014). Pengujian adaptasi beberapa klon karet pada masa tanaman belum menghasilkan. Jurnal Penelitian Karet, 32(1), 1-9.

Siagian, N., \& Bukit, E. (2015). Komparasi teknis dan finansial pengadaan benih melalui okulasi tanaman di polybag dengan okulasi di lapangan. Warta Perkaretan, 34(2), 115-126.

Sugiyanto, I., Sihombing, H., \& Darmandono. (1998). Pemetaan agroklimat dan tingkat kesesuaian lahan perkebunan karet. Prosiding Lokakarya Nasional Pemuliaan Karet 1998 dan Diskusi Nasional Prospek Karet Alam Abad 21, 201-222.

Suhendry, I. (2001). Pertumbuhan dan produktivitas tanaman karet pada beberapa tipe iklim. Jurnal Penelitian Karet, 19(1-3), 18-31.

Watson, W.A. (1989). Climate and soil. In C. Webster \& W. Baulkwill (Eds.), Rubber, Tropical Agriculture Series (pp. 125-164). Longman group.

Wijaya, T. (1996). Penerapan program komputer untuk estimasi potensi pertumbuhan tanaman berdasarkan ketersediaan air tanah. Informatika Pertanian, 6(1), 343-352.

Wijaya, T. (2008). Kesesuaian tanah dan iklim untuk tanaman karet. Warta Perkaretan, 30(2), 33-34.

Wijaya, T., \& Hidayati, U. (2012). Pemupukan. Dalam: Lasminingsih, M, Suryaningtyas, H, Nancy, C, \& Vachlepi, A. (Eds.), Saptabina Usahatani Karet Rakyat (6th ed.). Balai Penelitian Sembawa. 